\title{
IL-17D: A Less Studied Cytokine of IL-17 Family
}

\author{
Xuying Liu ${ }^{\mathrm{a}}$ Siyu Sun ${ }^{\mathrm{b}}$ Dongyan $\mathrm{Liu}^{\mathrm{a}}$ \\ aDepartment of Gastroenterology and Medical Research Center, Liaoning Key Laboratory of Research and \\ Application of Animal Models for Environmental and Metabolic Diseases, Sheng Jing Hospital of China Medical \\ University, ShenYang, China; bepartment of Gastroenterology, ShengJing Hospital of China Medical University, \\ ShenYang, China
}

\section{Keywords}

IL-17D $\cdot$ Cytokine $\cdot$ Inflammation $\cdot$ Tumor $\cdot$ Infection

\begin{abstract}
The interleukin-17 (IL-17) family is a relatively new family of cytokines consisting of 6 related factors (IL-17A-IL-17F), while the receptor family consists of 5 members: IL-17RA-IL17RE. IL-17A is the prototype member of this family, which is also the signature cytokine of T helper 17 (Th17) cells. Th17 cells are involved in the development of autoimmune disease, inflammation, and tumors. Although IL-17D is similar to IL-17A in its ability to induce inflammatory cytokine production, there are fewer studies on IL-17D. Recently, the role of IL-17D in tumors and infections has attracted our attention. Some knowledge of function of IL-17D has been gained by studies using nonmammalian species. In this review, we introduce the structural characteristics, expression patterns, and biological characteristics of IL-17D along with its potential function in the pathogenesis of disease.
\end{abstract}

Edited by: H.-U. Simon, Bern.

\section{Introduction}

Cytokines are small molecular proteins synthesized and secreted by immune cells and some nonimmune cells; cytokines serve as the main coordinators of the immune system. The interleukin-17 (IL-17) family is considered to be a unique family of cytokines that has significant immunological importance. IL-17A, the prototypic member of this family, was first identified in 1993 [1]. At present, 5 other members, IL-17B-IL-17F (shown in Fig. 1), have also been identified and cloned via human genome sequencing and proteomics [2-5]. Among them, IL-17F has the highest homology with IL-17A (40-55\%), followed by IL-17B (29\%), IL-17D (25\%), IL-17C (23\%), and IL-17E (17\%) [6, 7]. IL-17A, also commonly called IL-17, is mainly produced by $\mathrm{CD} 4^{+} \mathrm{T}$ cells, $\mathrm{CD} 8^{+} \mathrm{T}$ cells, and some immune cells. T helper 17 (Th17) cells not only produce IL-17A but also secrete IL-17F, IL-21, and IL-22 [8]. Both IL-17A and IL-17F are involved in the development of inflammation and host defense infection by inducing the expression of proinflammatory cytokines, chemokines, antimicrobial peptides, and matrix metalloproteinases by fibroblasts, endothelial cells, and epithelial cells $[9,10]$. IL-17A is involved in autoimmune, inflam- 


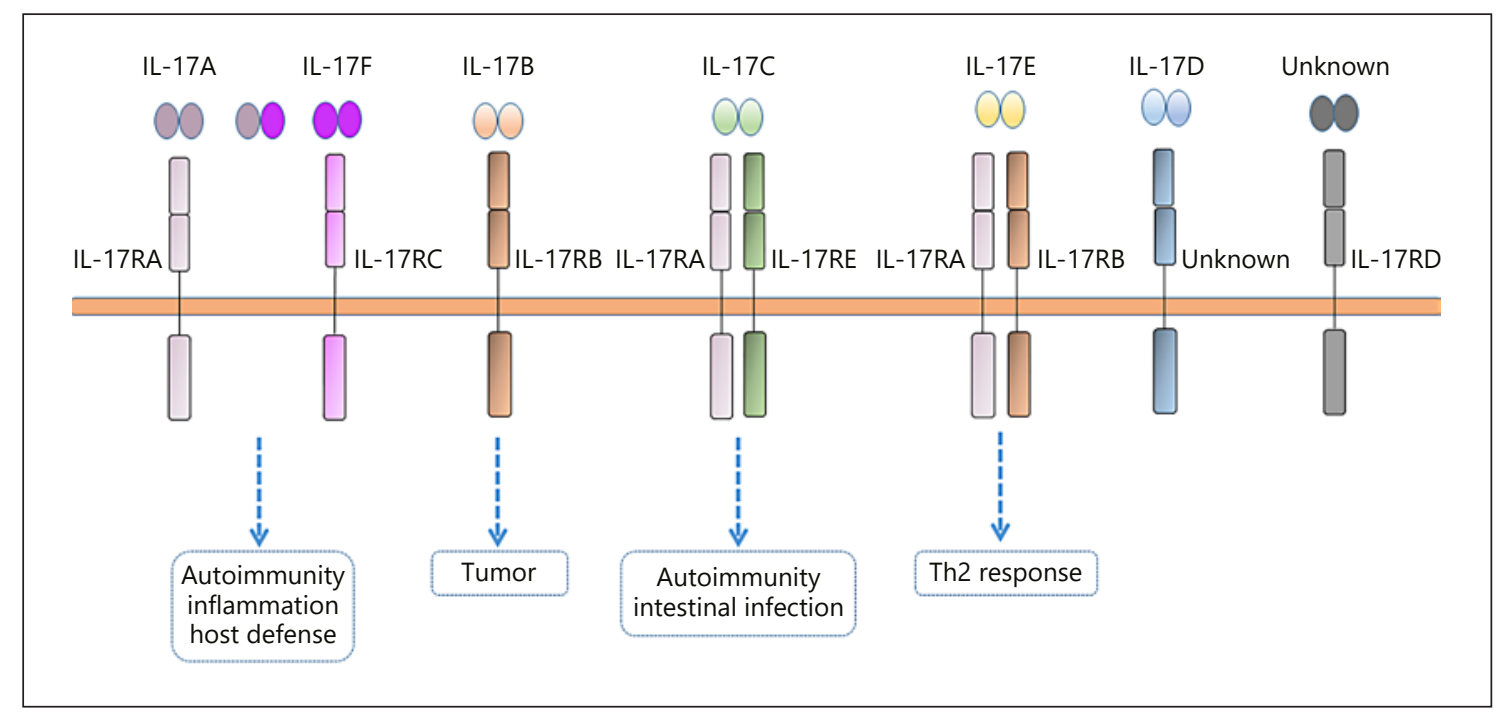

Fig. 1. IL-17 family cytokines and receptors. IL-17 family cytokines contain 6 members (IL-17A-F), and the receptor family consists of 5 members (IL-17RA-RE). IL-17A and IL-17F form homodimers or heterodimers to bind IL-17RA or IL-17RC, which leads to the upregulation of proinflammatory genes for host defense and the inflammatory pathogenesis of autoimmune diseases. Binding of IL-17B to IL-17RB promoted breast cancer cell invasion. IL-17C is essential for preventing intestinal infections and autoimmune diseases via IL-17RA and IL-17RE. IL-17E was believed to promote Th2 cell-type immune responses through the IL-17RA and IL$17 \mathrm{RB}$ heterodimer receptor complexes. The receptor for IL-17D and the ligand(s) for IL-17RD have not been identified. IL-17, interleukin-17. mation, and tumor development, while also playing an important role in host defense against bacterial and fungal infections [11, 12]; IL-17F is mainly involved in mucosal host defense [10]. The study found that the dual neutralization of IL-17A and IL-17F in psoriatic arthritis resulted in more effectively suppressing inflammation than the blockade of IL-17A alone, which indicated that IL-17F was similar to IL-17A in inducing an inflammatory response including the expression of proinflammatory cytokines and neutrophil recruitment [13]. IL-17B mRNA has been detected in adult human pancreas, small intestine, and stomach [2], although high expression was detected in chondrocytes and neurons [3, 14]. IL-17C is expressed in $\mathrm{CD}^{+} \mathrm{T}$ cells, dendritic cells, and macrophages at the site of inflammation, but not in most normal tissues $[2,15,16]$. Both IL-17B and IL-17C can induce the expression of TNF and IL-1 $\beta$ in monocyte cell lines and cause neutrophil infiltration $[2,3]$. IL-17E (IL25) is an amplifier of Th2 immune responses [9], which enhances type II immune responses by inducing cytokines (IL-4, IL-5, and IL-13) in auxiliary cells and induces IgE production and eosinophils, helping the host defend against nematodes and allergic diseases [17-19].

The IL-17 family of receptors consisting of IL-17RA, IL-17RB, IL-17RC, IL-17RD (SEF), and IL-17RE was also identified by the typical structural homology between members (shown in Fig. 1) [14, 20]. All receptor members include a fibronectin III-like domain in their extracellular domain and a SEF/IL-17R (SEFIR) domain in their intracellular region [21]. The SEFIR domain was previously identified as part of a cytosolic protein called Act1, which was identified as a key molecule for IL-17-mediated signaling [21, 22]. IL-17 family members act by binding to either homodimers or heterodimers of the IL-17 receptor family [23, 24]. IL-17A and IL-17F form homodimers or heterodimers to bind IL-17RA or IL-17RC, which leads to the upregulation of proinflammatory genes [25]. IL$17 \mathrm{C}$ is essential for preventing intestinal infections and autoimmune diseases via IL-17RE [26-28]. Binding of IL$17 \mathrm{~B}$ to IL-17RB promoted breast cancer cell invasion [29], while IL-17RB overexpression was associated with poor prognosis in patients with gastric cancer [30]. IL17E was believed to promote Th2 cell-type immune responses through the IL-17RA and IL-17RB heterodimer receptor complexes [31]. At present, the receptor of IL$17 \mathrm{D}$ is still unknown [32]; however, unlike other members of the IL-17 family, IL-17D possesses an extended C-terminal domain that can mediate unique receptor interactions [33]. Some studies have reported an interaction between IL-17D and IL-17RA, which indicates that 
Table 1. Nucleotide/amino acid identity of human IL-17D with IL$17 \mathrm{D}$ in other species

\begin{tabular}{llllll}
\hline Nucleotide/AA & 1 & 2 & 3 & 4 & 5 \\
\hline Human IL-17D & & 59.9 & 61.8 & 62.1 & 58.7 \\
Zebrafish IL-17D & 64.9 & & 65.7 & 67.9 & 84.4 \\
Atlantic salmon IL-17D & 50.5 & 65.4 & & 62.6 & 65.1 \\
Takifugu IL-17D & 45.0 & 59.8 & 64.9 & & 59.8 \\
Grass carp IL-17D & 52.5 & 85.3 & 66.7 & 55.8 & \\
\hline
\end{tabular}

IL-17, interleukin-17.

IL-17RA may be a potential receptor for IL-17D [34]. IL17D expression was detected in both teleosts as well as tetrapods [35-37]; thus, it is considered to be the most ancient member of the IL-17 family [38]. Homology analysis revealed that human IL-17D shared different similarities to other species IL-17D (Table 1), which shows that different species IL-17D have similar functions [35, $36,39,40]$. However, there is little knowledge available regarding the biological functions of IL-17D at present. In this review, we describe recent advances in the function of IL-17D, clarify its role in disease, and discuss areas for future research.

\section{Structural Characteristics and Expression of IL-17D}

All members of the IL-17 family share 4 highly conserved cysteine residues, which are involved in the formation of intrachain disulfide bonds. Human $I L-17 D$ was mapped to chromosome 13p11. As the largest member of the IL-17 family, IL-17D is a glycoprotein consisting of 202 amino acids, with a predicted monomer molecular weight of $26.3 \mathrm{kDa}$ and a dimer molecular weight of $52.6 \mathrm{kDa}$. IL-17D also has 4 other cysteine residues, which may participate in interchain disulfide linkages, thereby forming homodimers [33]. Starnes et al. [33] examined the expression of IL17D through RT-PCR. They observed that IL17D was highly expressed in skeletal muscle, brain, adipose tissue, heart, lung, and pancreas, while it was expressed at low levels in bone marrow, fetal liver, kidney, leukocytes, liver, lymph nodes, placenta, spleen, thymus, and tonsils. In addition, IL17D is also expressed at low levels in resting $\mathrm{CD} 4^{+} \mathrm{T}$ cells and resting CD $19^{+}$B cells. IL17D was poorly expressed in activated $\mathrm{CD} 4^{+} \mathrm{T}$ cells, resting and activated $\mathrm{CD} 8^{+} \mathrm{T}$ cells, resting and activated $\mathrm{CD} 14^{+}$monocytes, and activated $\mathrm{CD} 19^{+} \mathrm{B}$ cells [33].

\section{Biological Activities of IL-17D}

IL-17D did not seem to induce immune cell proliferation, but similar to other IL-17 family members, IL-17D had the ability to stimulate the production of other cytokines such as IL-6, IL-8, and GM-CSF [41]. It has been suggested that IL-17D plays a role in local immune responses because it can induce myeloid growth factors and chemokines, stimulating local infiltration and proliferation of leukocytes [33]. IL-17D suppressed the proliferation of myeloid progenitor cells as IL-17D increased IL-8 in an NF-kB-dependent manner [33]. IL-17D stimulated human umbilical vein endothelial cells to produce IL-8 to levels that were in the physiological range to inhibit hemopoiesis [42], while the levels of GM-CSF produced in human umbilical vein endothelial cells were 10 -fold lower than that required for stimulation of myeloid proliferation [43]. IL-17D plays a role in chronic anemia and sustained immune stimulation, while increased IL-17D resulted in decreased hemopoiesis; thus, IL-17D may play a direct or indirect role in regulating the hematopoietic response of inflammation by inducing the production of other cytokines [42, 44].

\section{Potential Roles of IL-17D in Diseases}

\section{IL-17D in Autoimmune Diseases}

The members of the IL-17 family have been implicated in autoimmune diseases, such as rheumatoid arthritis, systemic lupus erythematosus, psoriasis, and allogeneic rejection [10]. Although IL-17D has not been found in synovial fluid or peripheral blood mononuclear cells from patients with rheumatoid arthritis, it was detected in rheumatoid nodules $[15,45]$, and the potential pathogenic roles remain to be elucidated. However, mRNA expression of $I L 17 D$ was decreased in psoriatic skin [46]. These results indicate that IL-17D plays multiple roles in autoimmune disease, although future research studies to clarify its role are needed.

\section{IL-17D in Tumors}

Cytokine-based immunotherapy will become an important treatment for human cancer [47, 48]. IL-17D is a potential target for tumor immunotherapy as it was found that injection of recombinant IL-17D into B16-OVA melanoma cells transplanted into WT mice caused a significant growth delay as compared to control-treated tumors, demonstrating the antitumor effect of IL-17D [49]. Unlike the chemokines and cytokines expressed in immune 
cells, such as GM-CSF and IL-15 [50, 51], IL-17D is a cytokine that can be expressed by tumor cells. IL-17D stimulates production of monocyte chemotactic protein-1 (MCP-1), which recruits natural killer (NK) cells to the tumor microenvironment [52], and promotes M1 macrophage development and an adaptive immune response [49]. NK cells have been shown to promote antitumor T cell [53] and macrophage responses [54]. IL-17D-recruited NK cells primarily express high levels of CD27; chemokine receptor 3 (CXCR3) is thought to mediate the recruitment of $\mathrm{CD} 27^{\text {high }} \mathrm{NK}$ cells that secrete cytokines in lymph nodes $[55,56]$. The expression of CXCR3 ligands such as ITAC, MIG, and IP-10 can be induced by interferons (IFN) during tumor development [57]; therefore, IL-17D may also directly or indirectly induce production of IFN- $\gamma$ by NK cells to induce CXCR3 ligand expression on tumor cells. As a primary regulator of the response to oxidative stress [58], Nrf2 protects somatic and premalignant cells from carcinogenesis [59]. Analysis gene expression of fibrosarcoma cell lines treated with the chemical carcinogen, 3-methylcholanthrene (3-MCA), revealed that Nrf2 and IL-17D were coexpressed in murine tumor cell lines [60]. At the same time, Nrf2 activated by tertbutylhydroquinone (tBHQ), which was an antioxidant, resulted in an increase in $I L 17 D$ transcripts in a murine melanoma cell line (B16), a human Burkitt's lymphoma cell line (Ramos), and an MCA-induced sarcoma cell line (F244) [60]. Nrf2 not only directly bound to the IL17D promoter region but also was required for efficient induction of IL-17D by oxidative stress [60].

It has also been reported that IL-17D is expressed on neutrophils both in healthy subjects and patients with Bcell chronic lymphocytic leukemia. The expression of IL17D in neutrophils of patients was higher than that of healthy subjects [61], likely because IL-17D can affect the recruitment of neutrophils by inducing the production of IL-6, IL-8, and GM-CSF [33, 62]. Although studies investigating the role of IL-17 family cytokines in tumor progression have focused mainly on IL-17A, a major effect of IL-17A in the antitumor response is the recruitment of neutrophils [63]. IL-17D has previously been shown to play a role in the recruitment of neutrophils and other immune cells, such as NK cells, in tumors [52]. Based on these observations, the effective use of IL-17D for antitumor immunotherapy will depend on the specific clinical situation.

\section{IL-17D in Infection}

Studies have shown that mice deficient in IL17D exhibit signs of more severe infection after infection vac- cinia virus (VV) or murine cytomegalovirus (MCMV) as compared to WT mice [60]. At the same time, mouse cytomegalovirus infection induces the increase of $I L 17 D$ transcription in both fibroblasts [60] and peritoneal cells (mainly macrophages and B cells) [64] in vitro. These studies conclude that IL-17D mediates the early local recruitment of innate immune cells, which made mice more resistant to MCMV infection. Lee et al. [65] found that IL-17D exerted a pathogenic effect by inhibiting the activation of dendritic cells to reduce $\mathrm{CD} 8^{+} \mathrm{T}$ cells activity during Listeria infection. Therefore, the effect of IL-17D in infection may depend on both the specific pathogen and the nature of inflammation.

In chicken, following Eimeria maxima infection, IL17D transcript levels were increased in intestinal epithelial lymphocytes $\left(\mathrm{CD}^{+}, \mathrm{CD} 8^{+}\right.$, and $\mathrm{TCR} 1^{+}$cells), bursa, lung, and spleen but decreased in thymus. Treatment of chicken fibroblasts (CHCC-OU2) with chIL-17D recombinant protein induced the expression of IL- 6 and IL-8. These results indicated that IL-17D plays an important role in intestinal innate immunity during avian experimental coccidiosis [66].

Knowledge of IL-17D in lower vertebrates is limited. Grass carp IL-17D was preferentially expressed in mucosal tissues including skin, intestine, and gills; in addition, expression of IL-17D in head kidney and head kidney leukocytes was increased during in vivo bacterial infection and in vitro LPS treatment. Recombinant gcIL-17D increased gene expression of some proinflammatory cytokines such as $I L-1 \beta, T N F-\alpha$, and CXCL8 in grass carp primary head kidney cells. Recombinant gcIL-17D seems to activate the NF-kB signaling pathway by regulating the phosphorylation of $\mathrm{IkBa}$, thereby upregulating the expression of CXCL8 mRNA [40]. Moreover, IL-17D in Larimichthys crocea also increased the expression of the above chemokines and proinflammatory cytokines and mediated the migration of peripheral blood leukocytes [32], which further supported the immunoregulatory role of IL-17D in inflammation.

\section{Conclusion}

In this review, we summarize the structural characteristics, expression patterns, and biological activities of IL-17D and its role in disease. Recent reports have mainly focused on the role of IL-17D in tumors and infections. The Nrf2-IL-17D regulatory axis is activated during primary tumorigenesis and infection. It is likely that IL-17D can induce a more consistent antitumor re- 
sponse by recruiting NK cells, but its role in infection varies according to the specific type of pathogen and degree of inflammation present. Although there has been no research on the function of IL-17D in other diseases, future research on the endogenous role of IL-17D in infection, autoimmunity, and cancer and its regulation is necessary.

\section{Disclosure Statement}

The authors have no conflicts of interest to declare.

\section{Funding Sources}

This study was supported by the National Natural Science Foundation of China (81170604 and 30871158), the Education Department Foundation of Liaoning Province (LK201620), and the Outstanding Scientific Fund of ShengJing Hospital.

\section{Author Contributions}

Xuying Liu drafted the manuscript, Siyu Sun drafted and revised the article critically for important intellectual content, and Dongyan Liu gave the final approval of the submitted manuscript. All authors read and approved the manuscript and agree to be accountable for all aspects of the research in ensuring that the accuracy and integrity of any part of the work are appropriately investigated and resolved.

\section{References}

1 Rouvier E, Luciani MF, Mattéi MG, Denizot F, Golstein P. CTLA-8, cloned from an activated $T$ cell, bearing AU-rich messenger RNA instability sequences, and homologous to a herpesvirus saimiri gene. J Immunol. 1993 Jun 15;150(12):5445-56.

2 Li H, Chen J, Huang A, Stinson J, Heldens S, Foster J, et al. Cloning and characterization of IL-17B and IL-17C, two new members of the IL-17 cytokine family. Proc Natl Acad Sci U S A. 2000 Jan 18;97(2):773-8.

3 Shi Y, Ullrich SJ, Zhang J, Connolly K, Grzegorzewski KJ, Barber MC, et al. A novel cytokine receptor-ligand pair. Identification, molecular characterization, and in vivo immunomodulatory activity. J Biol Chem. 2000 Jun 23;275(25):19167-76.

4 Hymowitz SG, Filvaroff EH, Yin JP, Lee J, Cai L, Risser P, et al. IL-17s adopt a cystine knot fold: structure and activity of a novel cytokine, IL-17F, and implications for receptor binding. EMBO J. 2001 Oct 1;20(19):5332-41.

5 Lee J, Ho WH, Maruoka M, Corpuz RT, Baldwin DT, Foster JS, et al. IL-17E, a novel proinflammatory ligand for the IL-17 receptor homolog IL-17Rh1. J Biol Chem. 2001 Jan 12; 276(2):1660-4.

6 Kolls JK, Lindén A. Interleukin-17 family members and inflammation. Immunity. 2004 Oct;21(4):467-76.

7 Takatori H, Kanno Y, Watford WT, Tato CM, Weiss G, Ivanov II, et al. Lymphoid tissue inducer-like cells are an innate source of IL-17 and IL-22. J Exp Med. 2009 Jan 16;206(1):3541.

8 McGeachy MJ, Cua DJ. Th17 cell differentiation: the long and winding road. Immunity. 2008 Apr;28(4):445-53.
9 Starnes T, Robertson MJ, Sledge G, Kelich S, Nakshatri H, Broxmeyer HE, et al. Cutting edge: IL-17F, a novel cytokine selectively expressed in activated $\mathrm{T}$ cells and monocytes, regulates angiogenesis and endothelial cell cytokine production. J Immunol. 2001 Oct 15; 167(8):4137-40.

10 Iwakura Y, Ishigame H, Saijo S, Nakae S. Functional specialization of interleukin-17 family members. Immunity. 2011 Feb 25; 34(2):149-62.

11 Schofield C, Fischer SK, Townsend MJ, Mosesova S, Peng K, Setiadi AF, et al. Characterization of IL-17AA and IL-17FF in rheumatoid arthritis and multiple sclerosis. Bioanalysis. 2016 Nov; $8(22): 2317-27$.

12 Subbarayal B, Chauhan SK, Di Zazzo A, Dana R. IL-17 augments B cell activation in ocular surface autoimmunity. J Immunol. $2016 \mathrm{Nov}$ 1;197(9):3464-70.

13 Glatt S, Baeten D, Baker T, Griffiths M, Ionescu L, Lawson ADG, et al. Dual IL-17A and IL-17F neutralisation by bimekizumab in psoriatic arthritis: evidence from preclinical experiments and a randomised placebo-controlled clinical trial that IL-17F contributes to human chronic tissue inflammation. Ann Rheum Dis. 2018 Apr;77(4):523-32.

14 Moseley TA, Haudenschild DR, Rose L, Reddi AH. Interleukin-17 family and IL-17 receptors. Cytokine Growth Factor Rev. 2003 Apr; 14(2):155-74.

15 Hwang SY, Kim HY. Expression of IL-17 homologs and their receptors in the synovial cells of rheumatoid arthritis patients. Mol Cells. 2005 Apr 30;19(2):180-4.

16 Yamaguchi Y, Fujio K, Shoda H, Okamoto A, Tsuno NH, Takahashi K, et al. IL-17B and IL$17 \mathrm{C}$ are associated with TNF-alpha production and contribute to the exacerbation of inflammatory arthritis. J Immunol. 2007 Nov 15;179(10):7128-36.
17 Hurst SD, Muchamuel T, Gorman DM, Gilbert JM, Clifford T, Kwan S, et al. New IL-17 family members promote Th1 or Th2 responses in the lung: in vivo function of the novel cytokine IL-25. J Immunol. 2002 Jul 1; 169(1):443-53.

$18 \mathrm{Gu}$ C, Wu L, Li X. IL-17 family: cytokines, receptors and signaling. Cytokine. 2013 Nov; 64(2):477-85.

19 Song X, Qian Y. IL-17 family cytokines mediated signaling in the pathogenesis of inflammatory diseases. Cell Signal. 2013 Dec; 25(12):2335-47.

20 Song X, Qian Y. The activation and regulation of IL-17 receptor mediated signaling. Cytokine. 2013 May;62(2):175-82.

21 Gaffen SL. Structure and signalling in the IL17 receptor family. Nat Rev Immunol. 2009 Aug;9(8):556-67.

22 Chang SH, Park H, Dong C. Act1 adaptor protein is an immediate and essential signaling component of interleukin-17 receptor. J Biol Chem. 2006 Nov 24;281(47):35603-7.

23 Onishi RM, Gaffen SL. Interleukin-17 and its target genes: mechanisms of interleukin-17 function in disease. Immunology. 2010 Mar; 129(3):311-21.

24 Mensikova M, Stepanova H, Faldyna M. Interleukin-17 in veterinary animal species and its role in various diseases: a review. Cytokine. 2013 Oct; 64(1):11-7.

25 Zhu S, Qian Y. IL-17/IL-17 receptor system in autoimmune disease: mechanisms and therapeutic potential. Clin Sci. 2012 Jun;122(11): 487-511.

26 Chang SH, Reynolds JM, Pappu BP, Chen G, Martinez GJ, Dong C. Interleukin-17C promotes Th17 cell responses and autoimmune disease via interleukin-17 receptor E. Immunity. 2011 Oct 28;35(4):611-21. 
27 Ramirez-Carrozzi V, Sambandam A, Luis E, Lin Z, Jeet S, Lesch J, et al. IL-17C regulates the innate immune function of epithelial cells in an autocrine manner. Nat Immunol. 2011 Oct 12;12(12):1159-66.

28 Song X, Zhu S, Shi P, Liu Y, Shi Y, Levin SD, et al. IL-17RE is the functional receptor for IL-17C and mediates mucosal immunity to infection with intestinal pathogens. Nat Immunol. 2011 Oct 12;12(12):1151-8.

$29 \mathrm{Wu} \mathrm{HH}$, Hwang-Verslues WW, Lee WH, Huang CK, Wei PC, Chen CL, et al. Targeting IL-17B-IL-17RB signaling with an anti-IL17RB antibody blocks pancreatic cancer metastasis by silencing multiple chemokines. J Exp Med. 2015 Mar 9;212(3):333-49.

30 Bie Q, Sun C, Gong A, Li C, Su Z, Zheng D, et al. Non-tumor tissue derived interleukin-17B activates IL-17RB/AKT/ $\beta$-catenin pathway to enhance the stemness of gastric cancer. Sci Rep. 2016 May 5;6:25447.

31 Rickel EA, Siegel LA, Yoon BR, Rottman JB, Kugler DG, Swart DA, et al. Identification of functional roles for both IL-17RB and IL17RA in mediating IL-25-induced activities. J Immunol. 2008 Sep 15;181(6):4299-310.

32 Ding Y, Ao J, Chen X. Comparative study of interleukin-17C (IL-17C) and IL-17D in large yellow croaker Larimichthys crocea reveals their similar but differential functional activity. Dev Comp Immunol. 2017 Nov;76:34-44.

33 Starnes T, Broxmeyer HE, Robertson MJ, Hromas R. Cutting edge: IL-17D, a novel member of the IL-17 family, stimulates cytokine production and inhibits hemopoiesis. J Immunol. 2002 Jul 15;169(2):642-6.

34 Han Q, Das S, Hirano M, Holland SJ, McCurley N, Guo P, et al. Characterization of lamprey IL-17 family members and their receptors. J Immunol. 2015 Dec 1;195(11):544051.

35 Gunimaladevi I, Savan R, Sakai M. Identification, cloning and characterization of interleukin-17 and its family from zebrafish. Fish Shellfish Immunol. 2006 Oct;21(4):393-403.

36 Kumari J, Larsen AN, Bogwald J, Dalmo RA. Interleukin-17D in Atlantic salmon (Salmo salar): molecular characterization, 3D modelling and promoter analysis. Fish Shellfish Immunol. 2009 Nov;27(5):647-59.

37 Chi H, Bøgwald J, Dalmo RA, Zhang W, Hu YH. Th17 master transcription factors ROR $\alpha$ and ROR $\gamma$ regulate the expression of IL-17C, IL-17D and IL-17F in Cynoglossus semilaevis. Dev Comp Immunol. 2016 Feb;55:16978.

38 Roberts S, Gueguen Y, de Lorgeril J, Goetz F. Rapid accumulation of an interleukin 17 homolog transcript in Crassostrea gigas hemocytes following bacterial exposure. Dev Comp Immunol. 2008;32(9):1099-104.

39 Korenaga $\mathrm{H}$, Kono T, Sakai M. Isolation of seven IL-17 family genes from the Japanese pufferfish Takifugu rubripes. Fish Shellfish Immunol. 2010 May-Jun;28(5-6):809-18.
40 Du L, Qin L, Wang X, Zhang A, Wei H, Zhou $\mathrm{H}$. Characterization of grass carp (Ctenopharyngodon idella) IL-17D: molecular cloning, functional implication and signal transduction. Dev Comp Immunol. 2014 Feb; 42(2):220-8.

41 Aggarwal S, Gurney AL. IL-17: prototype member of an emerging cytokine family. J Leukoc Biol. 2002 Jan;71(1):1-8.

42 Broxmeyer HE, Sherry B, Cooper S, Lu L, Maze R, Beckmann MP, et al. Comparative analysis of the human macrophage inflammatory protein family of cytokines (chemokines) on proliferation of human myeloid progenitor cells. Interacting effects involving suppression, synergistic suppression, and blocking of suppression. J Immunol. 1993 Apr 15; 150(8 Pt 1):3448-58.

43 Shin HC, Benbernou N, Esnault S, Guenounou M. Expression of IL-17 in human memory CD45RO + T lymphocytes and its regulation by protein kinase A pathway. Cytokine. 1999 Apr;11(4):257-66.

44 Broxmeyer HE, Kim CH, Cooper SH, Hangoc G, Hromas R, Pelus LM. Effects of CC, CXC, $\mathrm{C}$, and $\mathrm{CX} 3 \mathrm{C}$ chemokines on proliferation of myeloid progenitor cells, and insights into SDF-1-induced chemotaxis of progenitors. Ann N Y Acad Sci. 1999 Apr 30;872:142-63.

45 Stamp LK, Easson A, Lehnigk U, Highton J, Hessian PA. Different T cell subsets in the nodule and synovial membrane: absence of interleukin-17A in rheumatoid nodules. Arthritis Rheum. 2008 Jun;58(6):1601-8.

46 Johansen C, Usher PA, Kjellerup RB, Lundsgaard D, Iversen L, Kragballe K. Characterization of the interleukin-17 isoforms and receptors in lesional psoriatic skin. Br J Dermatol. 2009 Feb;160(2):319-24.

47 Nicholas C, Lesinski GB. Immunomodulatory cytokines as therapeutic agents for melanoma. Immunotherapy. 2011 May;3(5):67390.

48 Rosenblatt J, McDermott DF. Immunotherapy for renal cell carcinoma. Hematol Oncol Clin North Am. 2011 Aug;25(4):793-812.

49 O'Sullivan T, Saddawi-Konefka R, Gross E, Tran M, Mayfield SP, Ikeda H, et al. Interleukin-17D mediates tumor rejection through recruitment of natural killer cells. Cell Rep. 2014 May 22;7(4):989-98.

50 Dranoff G, Jaffee E, Lazenby A, Golumbek P, Levitsky $\mathrm{H}$, Brose $\mathrm{K}$, et al. Vaccination with irradiated tumor cells engineered to secrete murine granulocyte-macrophage colonystimulating factor stimulates potent, specific, and long-lasting anti-tumor immunity. Proc Natl Acad Sci USA. 1993 Apr 15;90(8):353943.

51 Dranoff G. Cytokines in cancer pathogenesis and cancer therapy. Nat Rev Cancer. 2004 Jan; $4(1): 11-22$.

52 Saddawi-Konefka R, O'Sullivan T, Gross ET, Washington A Jr, Bui JD. Tumor-expressed IL-17D recruits NK cells to reject tumors. Oncoimmunology. 2014 Dec;3(12):e954853.
53 Diefenbach A, Jensen ER, Jamieson AM, Raulet DH. Rae1 and H60 ligands of the NKG2D receptor stimulate tumour immunity. Nature. 2001 Sep 13;413(6852):165-71.

54 O'Sullivan T, Saddawi-Konefka R, Vermi W, Koebel CM, Arthur C, White JM, et al. Cancer immunoediting by the innate immune system in the absence of adaptive immunity. J Exp Med. 2012 Sep 24;209(10):1869-82.

55 Martín-Fontecha A, Thomsen LL, Brett S, Gerard C, Lipp M, Lanzavecchia A, et al. Induced recruitment of NK cells to lymph nodes provides IFN-gamma for $\mathrm{T}(\mathrm{H}) 1$ priming. Nat Immunol. 2004 Dec;5(12):1260-5.

56 Watt SV, Andrews DM, Takeda K, Smyth MJ, Hayakawa Y. IFN-gamma-dependent recruitment of mature CD27(high) NK cells to lymph nodes primed by dendritic cells. J Immunol. 2008 Oct 15;181(8):5323-30.

57 Winkler AE, Brotman JJ, Pittman ME, Judd NP, Lewis JS Jr, Schreiber RD, et al. CXCR3 enhances a T-cell-dependent epidermal proliferative response and promotes skin tumorigenesis. Cancer Res. 2011 Sep 1;71(17):570716.

$58 \mathrm{Ma}$ Q. Role of nrf2 in oxidative stress and toxicity. Annu Rev Pharmacol Toxicol. 2013; 53:401-26.

$59 \mathrm{Ma}$ Q, He X. Molecular basis of electrophilic and oxidative defense: promises and perils of Nrf2. Pharmacol Rev. 2012 Oct;64(4):105581.

60 Saddawi-Konefka R, Seelige R, Gross ET, Levy E, Searles SC, Washington A Jr, et al. Nrf2 induces IL-17D to mediate tumor and virus surveillance. Cell Rep. 2016 Aug 30; 16(9):2348-58.

61 Garley M, Jabłońska E, Sawicka-Powierza J, Ratajczak-Wrona W, Kłoczko J, Piszcz J. Expression of subtypes of interleukin-17 ligands and receptors in patients with B-cell chronic lymphocytic leukemia. Clin Lab. 2014; 60(10):1677-83.

62 Goriely S, Goldman M. The interleukin-12 family: new players in transplantation immunity? Am J Transplant. 2007 Feb;7(2):278-84.

63 Fridlender ZG, Sun J, Kim S, Kapoor V, Cheng G, Ling L, et al. Polarization of tumorassociated neutrophil phenotype by TGF- $\beta$ : "N1" versus "N2" TAN. Cancer Cell. 2009 Sep 8;16(3):183-94

64 Seelige R, Saddawi-Konefka R, Adams NM, Picarda G, Sun JC, Benedict CA, et al. Interleukin-17D and Nrf2 mediate initial innate immune cell recruitment and restrict MCMV infection. Sci Rep. 2018 Sep 12;8(1):13670.

65 Lee Y, Clinton J, Yao C, Chang SH. Interleukin-17D promotes pathogenicity during infection by suppressing CD8 T cell activity. Front Immunol. 2019;10:1172.

66 Hong YH, Lillehoj HS, Park DW, Lee SH, Han $\mathrm{JY}$, Shin $\mathrm{JH}$, et al. Cloning and functional characterization of chicken interleukin-17D. Vet Immunol Immunopathol. 2008 Nov 15; 126(1-2):1-8. 